\title{
Predictors of Television Programmes Quality in Tanzania: Analysis of Stakeholders' Perspectives
}

\author{
Victor Eliah \\ School of Journalism and Mass Communication, University of Dares Salaam \\ Email: victoreliah@gmail.com
}

\begin{abstract}
There have been complaints over the quality of television programmes in Tanzania from various groups including; professionals, viewers, television programme sponsors and media authorities. Recognizing the role played by the availability of diverse programme quality perspectives on the amount such compliments, this study sought to establish an understanding on how stakeholders view quality in TV programmes. The study triangulated quantitative and qualitative methods in order to establish a better understanding. The study involved a total of 70 respondents that included; television programmes producers, television programmes viewers, programme sponsors, television programmes managers, and telecom/electronics engineers/technicians. The study has used questionnaire and interviews to collect data from these respondents. Based on the data collected, the study has found that the term "quality" in the context of television production is "erratic" due to the absence of specific standards for measuring it save for different perspectives of professionalism, viewers, business/sponsorships, editorial polices, creativity and cultural orientations. In order to sustain quality control, the study recommends among other things, the establishment of quality control boards or quality assurance unit by the government to spearheading standards in television production and bridge professionalism.
\end{abstract}

Keywords: Television programme, quality analysis, television programmes quality, quality control

https://dx.doi.org/10.4314/udslj.v16i2.13

\section{Introduction}

This article surveys predictors of quality of television programmes in Tanzania based on the criteria generally used to assess the quality of television programmes elsewhere. The concept of quality in television programmes as in other media is increasingly complex as there can be many perspectives and interests involved. Nevertheless, the concept is a vital one for anyone looking to ensure their programmes make an intended impact. This article presents the nexus of quality television programmes as an independent construct that is determined by the nature of television production practices. Ensuring quality in television programmes has positive effects on the industry and society because it helps to preserve societal norms and values and protect culture and 
television programme standards as well as promote professionalism. It is through these advantages that Bauer, et al. (2006) asserted that high quality of television programmes has positive effects on employees, customers, organizations and the community at large whereas poor quality programmes leads to loss of audience and moral degrade. Business-wise, the quality of television programmes is fundamental in sponsorship attraction, viewership boosting and enhancement of the reputation of stations or production houses to sponsors and viewers (Romero-Fresco, 2021; Sasamoto \& Doherty, 2016; Shamir, 2007; Gross, 2000; Ishikawa, 1996b).

However, quality in television programming is a complicated phenomenon. Unfortunately, this complexity increases daily in various parts of the world (Shamir, 2007). Several studies (e.g. Bayo-Moriones et al., 2018; Burns, 2011; Shamir, 2007; Mulgan, 1990) have revealed that the quality of television programmes is judged from different angles. Historically, this aspect was not a big deal in television production since there were limited television stations and programmes to fuel comparisons. For example, up until 1994, Mainland Tanzania had only three stations; DTV, ITV and Star TV (Hamdan, 2014; Sturmer, 1998). In contrast, there are more stations and numerous programmes now. More specifically, by May 2021, Tanzania had 50 registered television stations (TCRA, 2021). This has automatically given birth to comparisons.

Although problems in the quality television programmes are universal, there are conflicting ideas about the points of views from which the same is assessed. For instance, Shamir (2007) sees viewers rather than professionals, while Ishikawa (1996b) and Rosengren and Tagerud (1996) see professionalism in the production processes as the most central and important yardstick for assessing quality. Generally, there is no consensus when it comes to what to focus on when assessing the quality of television programmes.

Nevertheless, studies (See, Romero-Fresco, 2021; Marjaana, 2020; Hamdani et al, 2014; Msina, 2000; Owens, 2020) have indicated that the quality of television programmes is a matter of critical concern among media practitioners and the general public. As a matter of fact, the quality of these programmes in Tanzania has constantly been a source of many complaints from various stakeholders such as viewers, professionals, and regulatory authorities. In some cases, complaints about quality have highlighted televising unethical contents that threaten cultural norms, dignity, and the decency of the society. There have also been complaints about inappropriate content and technical problems (TCRA, 2019). These inadequacies jeopardize the intended roles (educating, informing and entertaining) of television programmes as per media obligations. In particular, the Tanzania Communication Regulatory Authority (TCRA) reports produced between 2016 to 2019 shows that several popular television stations have been fined for violations related to content production and broadcasting principles. Some of these stations are Independent Television (ITV), Azam Two, Clouds Television, Star TV, Channel Ten, East Africa TV and Gilly Bonny Online TV.

It is through these developments and the reported disparity in points of views regarding what entails quality TV programmes that the researcher was prompted to conduct this study to create an understanding of how quality in TV programmes is judged in Tanzania. To meet this goal, the study has analysed TV stakeholders' perspectives regarding the major predictors of quality in TV programmes in Tanzania by meeting the following specific objectives:

(i) Analysing stakeholders' perspectives on the determinants of quality television programmes.

Predictors of Television Programmes Quality in Tanzania: Analysis of Stakeholders' Perspectives

Victor Eliah 
(ii) Determining actors involved in the quality control of television programmes in
Tanzania.

\section{Related Literature}

The quality of a television programme is determined by how well it is written, acted, produced and its ability to educate and appeal to a broad audience (Burns, 2011). However, in television production, there are conflicting ideas on who is supposed to set quality assessment points. While Shamir (2007) sees viewers as more pivotal than professionals, Ishikawa (1996b) and Rosengren et al. (1996) consider the later as the most central quality measurement yardstick (See also, Romero-Fresco, 2021; Marjaana, 2020). On the others side, Wright (2006) shows that regulations and advertisements should have the impact on programmes' quality and viewers' welfare. From these arguments, it is easy to note that measurements of programmes' quality are set by many factors. Among these are culture and values of a certain place; meaning that television quality assessment is embedded in culture. Other factors as outlined by Mulgan (1990) in Shamir (2007) are: production values; viewers' preferences and market demand; quality as an aesthetic particular to the television medium; cherishment of communal values and social integration; high regard for individualistic participatory values; truth-telling and fairness; and, diversity. Similarly, Mulgan (1990) suggests a concept of quality that draws upon diversity, usability, and truth-telling. These factors attest to the fact that the quality of television programmes is a complex phenomenon.

According to Shamir (2007), this categorization is supported by the Japan Broadcasting Corporation (NHK), which examines television quality across cultures, methodological approaches, and television systems through three major perspectives on quality which are; the perspective of audiences, the point of view of professionals, and diversity. In all, it can be asserted that, the quality of television programmes is imbedded in societies' regulations and culture, evidenced in professionalism, viewers' perspectives, business orientation (especially programmes sponsorships), editorial polices, and societal values of a certain country.

\section{The empirical studies about quality of television programmes}

Studies from various parts of the world have raised concerns about television programmes' quality (See Owens, 2020; Romero-Fresco, 2021; Marjaana, 2020; Bayo-Moriones et al., 2018; Shamir, 2007). For example, Bayo-Moriones et al. (2018) conducted a study in Spain with focus on perceptions of the quality of different programmes broadcasted. The study revealed that viewers measured programmes' quality by: programmes' preservation of Spanish culture (26\%), good technical quality of the programmes $(22.2 \%)$, content $(6.9 \%)$ and commitment to society $(6.4 \%)$. These researchers also argue that the technical excellence associated with taste and aesthetics is considered as an important aspect when analysing quality from the perspective of professionals such as creators and members of juries. In connection to this view, Camacho (2005) was of the view that technically, the quality of television programmes should not be understood as elitist, rather, it can be achieved through formats, ideas, scripts, illumination, sound, photography and hosts. These studies are evidence of variations in discussions of quality of television programmes in various parts of the world. 
Another study on the quality of television programmes was carried out by Shamir (2007) in Israel. The study focused on assessment of television programmes quality and found that television programmes and genres tend to vary considerably in terms of the amount of time and money invested in their production. Likewise, a study on "Quality Standards for Children's programmes in the Writings of Television Critics", carried out in Netherlands by Peter et al (2006) further confirmed the lack of a unified perspective on this phenomenon. The study found that there were no consensuses on the standards that children's programmes should meet; rather, one has to make judgments based on different dimensions. In Australia, Bennett et al (2018) contended that, television programmes' quality assessment debates have questioned the exclusive output of television programmes by empirical engagement with experts and audiences while in the United States of America, several studies about the quality of television have been conducted. Fuller (2013) argues that quality in television programmes has not only become a dominant television format but also the benchmark against which "mainstream" television is measured. Thus, the quality of programmes is looked at from the angles of casting, scripting, acting, directing, producing and critical evaluation.

In Africa, a study by Abdulla (2014) showed that some Egyptians programmes were produced not from professionals' point of views but the will of the Government. The study also revealed that some programmes' scripts were written under government interferences and directives to shift focus on the governments' achievements while some channels (e.g. CBC) were burned for violating editorial policies. Another study carried out in Africa is one by Jesse (2006), which was carried out in South Africa with focus on poor quality of local television contents. Another one was carried out by Shobiye et al. (2018) who focused on "factors that influence one's choices in viewing public television in South Africa. These studies' findings on the compromised quality of TV programmes have been echoed by studies conducted in Kenya by Nyambane and Maende (2016) and in Uganda by Lugalambi et al. (2010).

Despite, the adversaries that work against efforts to ensure quality in television programmes, stations or production houses should have emphasized quality. These programmes are vehicles of the national development since for instance; quality programmes facilitate the delivering quality education. On this, Msina (2000:3) stated that "mass media, especially television contributes to the development of a nation". This implies that producing quality programmes contributes to development as long as the programmes are pro development and social change (See, Romero-Fresco, 2021; Marjaana, 2020; Sehl, 2020; Msina, 2000).

Generally, the quality of television programmes is a concern of producers, crew members, television managers, television stations or production houses, and the country at large. This means that the views of all these are important in the assessment and measurement of quality. Weinberg (1970) stated that quality can be measured in dimension, materials, properties, performance and so on. This shows that the aspect of quality was introduced to TV programming as early as 1960s when it was adopted from the industrial sector (Ahmed, 2003). However, despite this early introduction of this phenomenon to TV programmes production, there seems to be no single way of measuring quality in TV programmes. As such, amid complaints about the quality of TV programmes in Tanzania, there is a need for clear country-specific guidelines on what media houses should focus on when producing contents to air. Unfortunately, researchers have not paid much attention to this topic hence leaving a gap that this study sought to bridge.

\section{Research design and Methods}

Predictors of Television Programmes Quality in Tanzania: Analysis of Stakeholders' Perspectives

Victor Eliah 
The researcher subscribed to pragmatic epistemology whose orientation avoids purist tendencies of relying to either positivist or interpretive philosophies but embraces duality of both quantitative and qualitative methods respectively. Thus, this study employed a mixed method research approach (MMRA) to analyse perspectives of stakeholders on the quality of television programmes in Tanzania. Under this approach, both qualitative and quantitative procedures of collecting, processing, analysing and presenting data are simultaneous used (Creswell, 2012). The approach provided this study with the opportunity of gathering data by employing multiple tools that promised a better understanding of the phenomenon under study.

The study used the qualitative approach to get detailed data while the quantitative approach was used to quantify themes that emerged in relation to research objectives. In other words, the choice of the design that this study used was influenced by the advantages it presented to the study. The choice of the design permitted for the application of complimentary methods, convergence, and triangulation, which helped to neutralize and cancel biases of confining oneself to one data type. The concurrent use of quantitative and qualitative data increased robustness of results through cross validation. Quantitative data were used to quantify respondents. The data were collected through questionnaires especially closed questions. In contrast, qualitative data helped in the examination of programme qualities drawing from peoples' perceptions while leaving room for responses (Best \& Khan, 2004). In this regard, detailed data were generated from producers, production managers, television programmes viewers, and advertisers regarding their experiences with the quality of television programmes in Tanzania.

The study was conducted in Zanzibar and three regions in Mainland Tanzania; Dar es Salaam, Morogoro and Mwanza. The selection of these sites was influenced by their historical orientations and the number of television stations situated in them. According to TCRA (2020) and NBS (2020), these regions have more television stations and television sets than others. From these, five television stations and two production houses were selected for data collection based on how long the stations and production houses have existed, geographical locations, ownership, the nature and type of employment of producers, philosophical orientation of the media, and the availability and type of production equipment. Overall, the selection of stations and media houses was geared towards getting representatives that would provide the data required to meet the objectives of the study.

Selection of the sample of this study was done purposively to meet data requirements. Cohen et al (2000) describe sampling techniques as procedures followed when selecting elements of a population to represent the actual characteristics of the total population. This study selected a number of stations as seen here. Zanzibar Broadcasting Corporation (ZBC) was selected because it is the oldest television station in Tanzania from which information about how television production started and the experiences in television production were obtained. The study also included Tanzania Broadcasting Corporation (TBC1); a public-owned television station which is also believed to have qualified and experienced producers. Channel Ten and Star TV are private-owned television stations which together with Uhai Television (Azam Media) a new private media presented a different perspective for the study. The latter is also believed to have advanced and modern television production equipment and the production houses included; True Vision Production House and HaakNeel Production.

Thus, the sample consisted of 70 participants. To get the participants, the researcher used convenient sampling. Specifically, 38 television programmes producers, and 6 telecom and 
electronics engineers/ technicians were sampled. In addition to these, 7 television programmes managers ( 5 from television stations and 2 from production houses were selected), 7 television programme sponsors/advertisers were selected, 5 from Mainland Tanzania and 2 from Zanzibar. The researcher also picked 3 television viewers in each region so as to involve a total of 12 viewers in the study.

Television programmes producers were the key respondents of this study while the other groups complimented them. Whittaker (2017) contends that, although titles and responsibilities can vary the person in charge of launching and guiding the entire production is generally a producer. Such individuals come up with programmes ideas, they write proposals, do research, lay out budgets, write scripts, and organize and plans what should be done in all phases of programmes production. The individuals have strong interpersonal skills, they are good at long term planning and are organized and methodical; they are capable of visualizing the whole production process, and have knowledge of business and legal matters (See, Whittaker, 2017; Spann 2008 et al; Owens 2020). As such, this group of people was fundamental sources of data in this study. Hence, the 38 producers were given questionnaires and the rest respondents were interviewed.

This study used only two types of instruments to collect data - questionnaires and interviews. The instruments were chosen following this study's requirement of both qualitative and quantitative data. A questionnaire is used when factual information is desired. It is advantageous as it great ensures respondents' anonymity since it does not require face-to-face meetings between respondents and people collecting data. The questionnaire had both closed and open-ended questions so as to increase the reliability and validity of data (Nsubuga, 2000; Kumar, 2011). The open ended questions were used to give respondents an opportunity to give additional data that were not accommodated in closed questions. The study also used an interview guide to collect data. This instrument was used because it is quite flexible and can be easily adapted for respondents. The tool was also selected because some respondents were not able to complete questionnaires. This tool allows for the use of additional questions to gather missing data and it is useful to both literate and illiterate populations (Mason \& Bramble, 1997).

The study applied Borg and Gall's (2004) points of view, which advocates for descriptive data analysis. The data collected were organized, summarized and described in a manner that reflected the problem of the study based on research objectives. Descriptive data analysis dominated this stage of the study. The data were analysed with the help of Microsoft Office Excel 2010 and Microsoft Office Excel 2016 which were used to compute descriptive statistics such as frequencies and percentages. Additionally, the data were sorted and categorized in a narrative manner according to the information needed from respondents.

\section{Research Findings}

\section{Stakeholders' perspectives on the determinants of quality television programmes in Tanzania}

Television programmes producers were asked to explain what quality in TV programmes means for them. Responses obtained through questionnaires were coded and categorized as they appear in Table 1. As can be seen the table, there are various perspectives on what determines the quality of television programmes in Tanzania. This diversity makes the concept erratic. According to the 
findings, the quality of television programmes is determined by the degree of professionalism, cultural factors, viewers' opinions and viewership, programmes' attraction of sponsorship, editorial policy and creativity involved (see Table 1).

Table 1: Television producers' perspectives of television programmes quality determinants

\begin{tabular}{|c|c|c|c|c|}
\hline \multirow[t]{2}{*}{$\mathrm{S} / \mathrm{I}$} & \multirow{2}{*}{$\begin{array}{l}\text { Points of Quality } \\
\text { Measurements (n = } \\
\text { 38) }\end{array}$} & \multirow[t]{2}{*}{ Components } & \multicolumn{2}{|l|}{ Frequencie } \\
\hline & & & $\mathbf{s}$ & Percentage \\
\hline \multirow{6}{*}{1.} & \multirow{6}{*}{ Professionalism } & Video quality/pictures & 20 & 52.6 \\
\hline & & Sound quality & 16 & 42.1 \\
\hline & & Proper content & 11 & 28.9 \\
\hline & & Picture formats & 4 & 10.5 \\
\hline & & Quality editing & 5 & 13.1 \\
\hline & & Lighting & 0 & 0.0 \\
\hline \multirow[t]{2}{*}{2.} & \multirow[t]{2}{*}{ Culture } & Norms and values & 2 & 5.2 \\
\hline & & Acceptance by society & 3 & 7.8 \\
\hline \multirow[t]{2}{*}{3.} & \multirow[t]{2}{*}{ Viewers point of View } & Reach Audience & 4 & 10.5 \\
\hline & & Big viewership & 3 & 7.8 \\
\hline 4. & Business Point of view & Sponsorships & 3 & 7.8 \\
\hline \multirow[t]{4}{*}{5.} & Regulatory framework & Editorial policy & 1 & 2.66 . \\
\hline & \multirow{3}{*}{$\begin{array}{l}\text { Creativity Point of } \\
\text { View }\end{array}$} & Language usage & 2 & 5.2 \\
\hline & & $\begin{array}{l}\text { Selection of good } \\
\text { presenters }\end{array}$ & 2 & 5.2 \\
\hline & & Uniqueness & 1 & 2.6 \\
\hline
\end{tabular}

\section{Source: Field data}

Professionalism perspectives 
Generally, the results in the Table 1 suggest that there are diverse determinants of quality in television programmes. In particular, the results show that a number of professionalism attributes in TV programmes are important quality determinants. These have included the quality of the video or the pictures $(52.6 \%)$, sound quality $(42.1 \%)$ and content viewers $(28.9 \%)$. Furthermore, the results show that less than one fifth $(<20 \%)$ of respondents indicated quality editing, captions and pictures formats, lighting, viewership, acceptance by society, sponsorships and editorial policies as determinants of television programmes quality. Some engineers believed that, video and sound influences the quality of the programmes to a great extent, for instance one engineer was quoted saying;

Equipment has $90 \%$ influences on programmes production quality. The first equipment is the camera. Currently, the camera talk in Africa and Europe is about $4 K$ while for some countries in Asia they have gone up to $8 \mathrm{~K}$. This is the aspect ratio that gives a quality picture as compared to the pictures produced by HD or SDI. (Engineer 1: 02/03/2021).

\section{Cultural perspectives}

Under cultural factors, participants appear to suggest that cultural issues are not much critical in determining the quality of television programmes. As indicated in table 1 , only $5.2 \%$ of the respondents mentioned norms and values and $7.8 \%$ mentioned society's acceptance of programmes as quality measurements. Surprisingly, this was contrasted by all the 12 viewers interviewed by this study. These participants highlighted the respect given by programmes to norms, traditions, and customs as an important determinant of the quality of television programmes. For instance, one viewer was quoted saying;

I can say there are good and poor quality programmes on our television screens. Culture values are very important and they need to be accommodated in these programmes. For example, entertainment programmes are very problematic. In most cases musicians' clothing is against our culture. Therefore, producers need to look at this to ensure they produce programmes that protect our norms, our status, and our culture for future generation (Viewer 1: 01/03/2021).

Adding on the same perspective, another viewer added that "the quality of our programmes is measured by many things like its production, content, and the cultural setup of the society and cultural practices" (Viewer 2: 28/02/2021).

These quotations show that there is a disparity between how programme producers see quality in TV programmes and how the same is viewed by viewers. This is very likely to fuel complaints because there are minimal chances of viewers getting what they expect if producers' expectations are this different from there's.

\section{Viewership and viewers' perspective}

The study has also found some producers use this component a quality measurement basis. Specifically, $10.5 \%$ of the producers said that a quality programme is one that reaches audience

Predictors of Television Programmes Quality in Tanzania: Analysis of Stakeholders' Perspectives

Victor Eliah 
and $7.8 \%$ identified the number of viewers as important. However, the frequencies at which these factors were mentioned suggest that these factors are not strong determinants of the quality programmes. Nonetheless, interviewers with viewers revealed that people like programmes to meet their interests. In this vein, it was unveiled that viewers' perspectives of quality were highly depended on their political affiliations as opposed to professionalism or cultural considerations. For instance, some viewers accused one station for poor quality of television programmes just because the programmes do not have content on their favourite political parties. One viewer said the following on this:

Some television stations have very poor programmes. For example, one station is just airing programmes with the ruling party's content while ignoring our party. I can say such stations are not doing us their viewers any justice. I regard them as poor producers! They don't consider the interests of the masses (Viewer 1: 28/02/2021).

Another viewer had the following observation:

To me, the quality of television programmes must be judged on the basis of their ability to air news of our interests. For example, some stations are just showing western dramas, music and films. How can I say that this is a quality programme while I don't know their intention, (Viewer 2: 01/03/2021)?

These statements indicate that quality is a very subjective aspect. In addition to this, the results show a huge divergence between producers' view of quality and that of viewers. This is only going to perpetuate quality related complaints from the later.

\section{Editorial Policy perspective}

This was the least mentioned determinant of quality since only 1 producer out of the 38 which equals to only $2.6 \%$ of the producers mentioned that quality is determined by editorial policies and the extent to which the policies and guidelines are adhered to. As revealed earlier in this study, television production is also guided by the editorial polices. The TCRA reports of 2016 to 2019 show that several television stations were charged or banned for example for not abide by these policies and guidelines. Surprisingly, producers do not consider them as important aspects of quality of TV programmes.

\section{Business perspective (Programmes Sponsorships)}

According to these findings, programmes that attract sponsors are seen as high quality ones regardless as evidenced by $7.8 \%$ of producers who identified this as a quality measurement point. Although this factor looks like a weak determinant based on the number of producers that pointed it out, interviews with sponsors cemented its value. For instance, one television programmes sponsor shared the following: 
We have the experience of sponsoring various television programmes on various television stations in Tanzania. The criteria we use to pick the programme to sponsor are the size of viewership. We however use the nature of programmes' content. We are interested in sponsoring programmes that are related to our products (Sponsor 1: 03/03/2021).

In the same vein another television programmes sponsor narrated that:

We pool out our sponsorship as soon as we feel that the quality of a programme has dropped. We also consider what time is a programme is aired and where we can meet audience when determining if we would love to associate ourselves with a programme or not, (Sponsor 2: 19/04/2021).

Generally, while producers appear to consider sponsorship as a minor determinant of quality, the views of these entities appear to have a strong influence on what is put into programmes and other logistics associated with the programmes. In addition to that, responses from sponsors show that viewership is a very important quality determinant.

\section{Creativity perspective}

The Findings further show that $5.2 \%$ of producers mentioned language usage as a determinant of the quality of programme content while another 5.2\% mentioned good selection of presenters and $2.6 \%$ mentioned uniqueness. On the whole, creativity in television production encompassed these three components; language usage, exceptional selection of presenters and uniqueness.

\section{Actors and their Roles in Quality Control and Assurance in Television Programmes}

In an attempt to know who assesses and controls the quality of television programmes in Tanzania, the researcher developed a question which asked television programmes producers about actors and their roles in the quality of the programmes they produce. The same question was asked to television managers during interviewers. The findings generated from the data collected have indicated that the control of television programmes quality in Tanzania is under television programmes managers, Tanzania Communication Regulatory Authority (TCRA), viewers, and television programme producers. Apart from identifying these actors, the study has described their roles in quality control and quality assurance. Table 2 presents findings on this aspect.

Table 2: Actors in television programmes quality control in Tanzania

\begin{tabular}{llccc}
\hline S/N & $\begin{array}{l}\text { Programmes Quality Controller/ } \\
\text { Critique }\end{array}$ & Frequencies & Out of & Percentages \\
\hline 1. & $\begin{array}{l}\text { Manager of Television/Production } \\
\text { Manager }\end{array}$ & 23 & 38 & $60.5 \%$
\end{tabular}

Predictors of Television Programmes Quality in Tanzania: Analysis of Stakeholders' Perspectives

Victor Eliah 


\begin{tabular}{llccc}
\hline \hline 2. & Tanzania Communication Regulatory & 3 & 38 & $7.89 \%$ \\
& Authority (TCRA) & & & \\
3. & Audiences/Viewers & 9 & 38 & $23.6 \%$ \\
4. & Television Programmes Producers & 10 & 38 & $26.31 \%$ \\
\hline
\end{tabular}

\section{Source: Field Data}

The findings in Table 2 show that the quality of TV programmes is mainly assessed and controlled by television managers or production managers. More specifically, the findings show that $60.5 \%$ of producers that took part in this study identified their managers as the assessors of the quality of their programmes. The findings further show that $26.31 \%$ of the producers indicated that they themselves\% are the quality controllers while $7.89 \%$ identified TCRA as the one in charge of quality and $23.6 \%$ said this role was played by views of viewers. On the other hand, findings generated from interview held with television managers, sponsors and viewers revealed other programmes quality assessors; Media Council of Tanzania (MCT) and the viewers themselves. Speaking on this, one interviewee was quoted saying:

Sometimes we have been using Media Council of Tanzania (MCT) to assess the quality of our programmes through excellence in Journalism awards held every year. We encourage our producers to participate. We have been wining in several categories and therefore we regard ourselves as good programmes producers" (Television Programmes Manager 1: 21/04/2021)

\section{Quality control Units in Television stations and Production Houses}

Having a well-established in-house quality control unit was the other approach some media houses used in their quality control. However, during interviews with television managers, it was revealed that only 3 out of the 5 sampled television stations had such units. Out of the 3 , only 1 station had a steady control unit. In this station, a special arrangement is supposed to be followed by the producers and other programme controllers before programmes are broadcasted. For the production houses, all the two had steady quality control units. Programmes were previewed by a team of five to six production crews before being sold or sent to costumers that ordered their production. Generally, in all the stations and production houses, the study has found some quality control weaknesses. Firstly, there is absence of effective quality control units. Secondly, televisions stations and production houses depended much on producers as programmes previewers. Thirdly, there were no steady chief programmes editors (PE) and television managers were used a previewers of the programmes although they are not the right people for such a task. Fourthly, some producers are being used as the experts of everything. They work as the programmes producers, editors, directors, sound experts and sometimes as camera personnel.

The study has revealed that, quality control, especially for independent producers, was done by some of the unqualified producers. For example, some producers were untrained and unqualified for the job but still tasked to edit and design graphics. This negatively impact the quality check done on programmes. 


\section{Discussion}

The study has explored predictors of television programmes quality in Tanzania from the perspective of points on which quality assessment is based. The study has reveals a number of television programmes quality predictors. In particular, the study has revealed that video or picture, sound, content and lighting quality are the main predictors for TV programmes quality. This implies that the quality of television programmes depends on production aspects looked at from professionalism point of view. This corroborates findings made by preceding studies (Zettl, 2012; Spann et al., 2008; Owens, 2020). In particular, studies by Owens and Millerson, (2008) and Aarreniemi-Jokipelto, (2009) opined that the quality of television programmes support the delivery of messages. According to the study, $13.1 \%$ of respondents opined that editing determines the quality of television programmes and makes a major contribution to the effectiveness of any production. In contrast, poor editing bores viewers and damages the reputation of television stations (Millerson, 2001). On a different note, the study's identification of sponsors as minor determinants of quality is surprising because it very difficult to separate sponsors role from that of viewership. Moreover, viewership itself has been identified as a major determinant. However, viewership alone is contributed to by various factors and may not guarantee aspects like protection of traditions like family norms and customs.

The study findings affirm that creativity is the beauty of content presentations although only $5.2 \%$ of producers involved in the study mentioned language usage and good selection of presenters as quality determinants while only $2.6 \%$ mentioned uniqueness. Although producers had an unsatisfying view of the importance of creativity in determining quality of TV programmes, interviewees recognised its importance. As such, the finding are in line with those from a study by Parish and Taylor (2007) who reported that creativity is characterized by the ability to present the world in new ways, to find hidden patterns, to make connections between unrelated phenomena and to generate solutions. Creativity in television production covers language usage, exceptional selection of the presenters and uniqueness. As such, although creativity was less considered as a determinant of the quality of television programmes, it creates originality, fresh formats and techniques for programmes. The study has also revealed that the quality of television programmes is also determined by other players including, television programmes managers, Media Council of Tanzania (MCT), producers and viewers. In general, the study suggests that the quality of TV programmes is a responsibility of a group of individuals. These, each in their respective position play a role.

Among the players identified, television managers are the supervisors of programmes production. Their production roles include; coordinating production teams, supervising production activities, previewing programmes before they go on air, deciding which programmes should go on air, and content moderating. Similarly, Mitchell (2009) and Owens (2020) argued that a production manager provides a reliable, factual, and theoretical framework for understanding programmes production based on a unique overview of production, oversight and its responsibilities like the parameters of time and budget and all the production execution schedules. Apparently, television production managers are the engine of the quality of television programmes and they are the think-tanks of television programmes production (Owens, 2020; Whittaker, 2017; Orlebar, 2002). A producer comes up with programmes ideas through proposal writing, research, and script-writing (Whittaker, 2017; Spann 2008 et al; Thomson \& Dowen, 2009).

Predictors of Television Programmes Quality in Tanzania: Analysis of Stakeholders' Perspectives

Victor Eliah 
On the other hand, TCRA as an actor in quality determination has the mandate of regulating the postal and broadcasting electronic communication, and is responsible for protecting the interests of consumers. TCRA is a quasi-independent government body responsible for regulating communication and broadcasting sectors (TCRA, 2020). Despite that mandate, it has been noted that TCRA does not have a direct mechanism for controlling the quality of television programmes except when rules and regulation of broadcasting have been violated by television or media houses. It is from this perspective that, Dale and Plunkett (1990:3) asserts that "quality control involves operational techniques and activities aimed both at monitoring process and eliminating causes of unsatisfactory performance."

Although TCRA has the mandate to punish wrong dowers, the body has limited effect on quality. For example, TCRA cannot control and assure quality with regards to technical aspects like sound problems, lack of creativity, poor lighting and poor programmes contents. Overall, this study concurs with others that revealed that the quality of TV programmes is a responsibility of many actors (See, Romero-Fresco, 2021; Bayo-Moriones et al., 2018; Marjaana, 2020; Sehl, 2020; Owens, 2020).

Viewers are the emerging controllers and critiques of the quality of television programmes despite being mentioned by only $23.6 \%$ of producers that participated in this study. Several scholars like Shamir (2007), Gross (2000), Bayo-Moriones et al., (2018) and Ismail (2017) have mentioned viewers as critical actors in the control of television programmes quality. Viewers have been raising their voices though social media to criticize or praise television programmes based on their views or social settings. In fact, viewers have been mentioned as one of the references of programmes quality critiques because they are the consumers of the programmes.

The Media Council of Tanzania (MCT) has been criticizing the poor quality programmes and also has been preparing the competition awards for quality programmes. Indeed, while awards are known for propagating professionalism and creativity, there is a need for establishing more proactive approaches to quality control and enforcement that may have a direct impact on quality of television programmes. Indeed, it was noted that, the television programmes critique has no special academic point or board in Tanzania which is assigned to assessment the quality of television programmes in Tanzania, the controllers and the assessors above have at certain points of limit that cannot control every aspect in television station or television houses.

\section{Study Implications and limitations}

Since television production is growing rapidly in Tanzania, this study adds on the body of literature that informs the media industry about the quality of television production in Tanzania. Practically, the study is useful as a reference and guideline for media house operators. The study can be useful to television programmes producers, production managers, and all media practitioners seeking to produce quality television programmes.

This study was confined to only 5 television stations and two production houses and a sample of 70 respondents. As such, its results may not be generalized. In other words, the usage of this study's findings when speaking about the general view of television programme quality in Tanzania should be done with caution. A longitudinal study is required to establish a better understanding of this phenomenon in Tanzania. 


\section{Conclusion and Recommendations}

Perspectives gathered from participants have indicated a lack of consistency and overlaps in how the concept of television programmes quality is seen. Clearly, professional perspectives, despite their prominence, need stronger advocacy and mainstreaming in order to withstand the pressure exerted by viewership as preferred by television programmes sponsors. Apparently, strict emphasis on viewership as a determinant of quality of programmes may not guarantee required quality of television programmes needed. Media policies need to set a minimum quality threshold for quality control that is independent of viewership factor alone.

Based on the findings of this study, it has been seen that there is a need for strengthening internal quality control mechanisms for more efficiency by having programme editors (PE) to work on both content and technical aspects of programmes under the supervision of programmes managers. There is also a need to streamline efforts and ensure uniformity of practices by TCRA by compulsory establishment of quality control units/departments which will be responsible for eliminating poor programmes, previewing the programmes to establish their appropriateness and compliance with all requirements that make a television programme like; topic relevance, content, language, shots, sound, light, graphics, caption, promotion sequencing and abidance to editorial policies.

\section{References}

Abdulla, R. (2014).Egypt's Media in the Midst of Revolution.CarnegieEndowment for International Peace. Retrieved from:https://carnegieendowment.org/2014/07/16/egypt-smedia-in-midst-of-revolution-pub-56164

Ahmed, A. (2003). Quality control experience in Tanzania industries. Master's Dissertation, University of Dares Salaam.

Bennett, T., Gayo, M., and Rowe, D. (2018).Television in Australia: Capitals, tastes, practices and platforms:Media International Australia: Retrieved from https://www.academia.edu/47141153/Television_in_Australia_capitals_tastes_practices_and platforms

Bauer, E. J, Duff, L. G \& Westcott, T.R. (2006). The Quality Improved Handbook (2 ${ }^{\text {nd }}$ Edition) ASQ Quality Press Milwaukee.

Bayo-Moriones, A, Etayo, C \&Sánchez-Tabernero, A. (2018). Revisiting quality television: Audience perceptions.International Journal on Media Management20 (3),193 - 215.

Best, J. W. \& Kahn, J.V. (2004). Research in Education.Prentice hall of India.

Borg, W. R. \& Gall, M. D. (2004). Educational Research: An Introduction. Longman.

Burns, C. (2011). A definition of quality television using current television. Retrieved from: www.academia.ed

Cohen, L., Manion, L., \&Morrison, K. (2007). Research Methods in Education (6 ${ }^{\text {th }}$ edition). Routledge.

Creswell, J.W. (2012). The Use of Multi-Methods Makes the Findings More. Routledge.

Dale, B. G \&Plunkett, J.J. (1990). Managing Quality Prentice.Hall of India.

Fuller. S. (2013). Quality TV: The Reinvention of U.S. Television.The University of Sydney

Predictors of Television Programmes Quality in Tanzania: Analysis of Stakeholders' Perspectives

Victor Eliah 
Gross, S.L (2000) Telecommunications: An introduction to Electronic Media (7 ${ }^{\text {th }}$ edition). McGraw Hill.

Hamdani, M. M., Rashid, A., \& Amour, F.S. (2014). History of Zanzibar Media, Traditions and Transition. Media Council of Tanzania (MCT).

Ishikawa, S. (Ed.). (1996b). Quality Assessment of Television. John Libbey Media

Ismail, N. (2017). Egypt's State-Owned Television: A Call for Reform. [Master's Thesis, the American University in Cairo]. AUC Knowledge Fountain: Retrieved from https://fount.aucegypt.edu/etds/375

Jesse, G. (2006).How has multichoice Africa affected the way people view television in African countries?Master's dissertation, Grand Valley State University. Retrieved from Retrieved from http://scholarworks.gvsu.edu/theses/638

Kumar, R. (2011). Research Methodology: A step by Step Guider for Beginners. (3 ${ }^{\text {rd }}$ Edition). Sage Publications India Pvt Ltd.

Lugalambi, W, G, Mwesige, P, G \&Bussiek, H (2010). Public Broadcasting in Africa Series, Open Society Initiative for East Africa. Retrieved from https://www.opensocietyfoundations.org/uploads

Marjaana, M. (2020).The Good Television: Factual Programmes, Quality and Subjective Experience. Helsinginyliopisto

Millerson, G. (2001). Video Production Handbook ( $3^{\text {rd }}$ edition). Focal Press.

Mitchell, L. (2009). Production Management for Television. Taylor and Francis Group.

Msina, V. (2000). The impact of mass media on culture in Tanzania: A case study of television in Dar es Salaam. Master's Dissertation, University of Dares Salaam.

Mulgan, G. (1990). Television's Holy Grail: Seven types of quality. In Geoff, M. (Ed.), The Question of Quality. British Film Institute.

Nsubuga, E.H.K. (2000). Fundamental of educational research. MKPublisher (U) Limited.

Nyambane, M, M. \&Maende, J. W. (2016). The impact of locally generated television programmes on the Kenyan television viewers: A case study of citizen television. University of Nairobi. Volume.5, (1726-1736)https://www.semanticscholar.org/paper/

Owens, J \&Millerson, G. (2008). Video Production Handbook ( $4^{\text {th }}$ Edition). Elsevier.

Owens, J. (2020). Television Production (17 ${ }^{\text {th }}$ Edition). Taylor and Francis Group.

Orlebar, J. (2002). Digital Television Production: A handbook. Oxford University Press Inc.

Parish, J.R. \& Taylor, A. (2007). Career Opportunities in Television and Cable. InfoBase Publishing.

Peter, N, Tom, H.A. \&Voort, D.V. (2006). Quality Standards for Children's Programmes in the writings of Television critics. Journal of Educational Media. 24(1), 7-23. Retrieved from https://doi.org/10.1080/1358165990240102

Romero-Fresco, P (2021) Negotiating quality assessment in media accessibility: The case of live subtitling. Universal Access in the Information Society 20(2), 741-751. DOI: 10.1007/s10209020-00735-6

Rosengren, K.E, Carlossn, M. \&Tagerud, Y. (1996). Quality in programming: Views from the North.In Ishikawa, S(Ed) Quality Assessment of Television.JohnLibbery Media. 
Sasamoto, R\& Doherty, S. (2016). Towards the Optimal use of Impact Captions on TV Programmes. In O'Hagan, M. \& Zhang, Q. (Eds.), Conflict and Communication: A Changing Asia in a Globalisingworld.Nova Science Publishers.

Sehl, A. (2020). Public Service Media in a Digital Media Environment: Performance from an Audience Perspective. Media Performance in Times of Media Change. 8 (3), 359- 372. DOI: https://doi.org/10.17645/mac.v8i3.3141

Shamir, J. (2007). Quality assessment of television programmes in Israel: Can viewers recognize production value?Routledge.

Shobiye, T., Naidoo, G. M., \&Rugbeer, H. (2018). Factors that influence one's choice for viewing public television in South Africa.25 (1), 394 - 424. Retrieved from

https://doi.org/10.29086/2519-5476/2018/v25n1a16

Spann, T.; Maynard, R.; \&Ronald, R. (2008). Fundamentals of Television Production ( $2^{\text {nd }}$ edition). Pearson education Inc.

Sturmer, M. (1998). The Media History of Tanzania.Ndanda Mission Press.

Tager, M. \& Chasi, C. (2015). Tuning in perspectives on television in South Africa. Pearson.

Thomson, L. \& Dowen, E. (2009). What's like to be a TV producer? Blake Education Pty Ltd.

URT (2020), National Bureau of Statistics: House Hold Budget Survey 2017/2018, Mainland Tanzania.

URT (2019), TCRA Reports of 2016 - 2019. Retrieved from tcra.go.tz/publications-and-statistics

URT (2021), TCRA Quarterly Communications Statistics, April -June 2021.Retrieved from https//www.tcra.go.tz

Weinberg, S. (1970). Profit though Quality. Gower press.

Wright, J.D. (2006). Television advertising Regulations and the Programmes Quality. Sydney University Press.

Whittaker, R. (2017). Television production: A free interactive course in studio and field.Cyber Collage and International Campus. Retrieved from https://www.cybercollege.com

Zettl, H. (2012). Television Production Handbook (11 ${ }^{\text {th }}$ Edition). Cengage Learning. 